\title{
IMPLEMENTASI REPOSITIONING L-MEN DALAM KEGIATAN KOMUNIKASI PEMASARAN
}

\author{
Mega Farras Nur Ihsani, Hanny Hafiar, Anwar Sani \\ Program Studi Hubungan Masyarakat \\ Fakultas Ilmu Komunikasi Universitas Padjadjaran \\ Email: megafarras@hotmail.com
}

\begin{abstract}
This research purpose is to know the communications strategy of L-Men, the product attributes of L-Men, and the positioning statement of the L-Men product in their repositioning strategy.

The method used in this research is descriptive with qualitative data. The subject of this research is individuals involved in the implementation of L-men's repositioning, from the process of planning to implementation. The Data is obtained through passive participant observation, semi-structured interview, and literature.

The result of this research shows that L-Men repositioning communication strategy with management L-Men consisted of brand marketing, digital, public relations, customer relations, promotions, and involvements of Perbasi and nongym athletes as communicator, to bring out the message that L-Men is a product for those who desire ideal and athletic body shape, through media and face to face interaction with audience through events and programs, with target audiences ranging from 17 years old until 35 years old male who partake in healthy lifestyle and the needs of nutrients for the formation of muscle mass and improving sports performance, with the end goals of increasing the product awareness and also the number of sales. The attributes that L-men possessed in its repositioning strategy are packaging design, advertising concept, content marketing, and event. The repositioning as stated by the positioning statement is "Effective Nutrients for Male Ideal and Athletic Body Shape".
\end{abstract}

Keywords: implementation, repositioning, attribute

\begin{abstract}
Abstrak
Tulisan ini bertujuan untuk mengetahui bagaimana strategi komunikasi yang dilakukan L-Men, bagaimana atribut-atribut produk yang disampaikan L-
\end{abstract}


Men, serta untuk mengetahui bagaimana positioning statement baru yang dimiliki L-Men dalam menerapkan repositioning.

Metode penelitian yang digunakan adalah deskriptif dengan jenis data kualitatif. Subjek dalam penelitian mengenai hasil repositioning L-Men ini merupakan individu yang terlibat dalam pelaksanaan repositioning, dari masa perencanaan hingga pelaksanaan. Pengumpulan data diperoleh melalui observasi partisipasi pasif, wawancara semi terstruktur, dan studi pustaka.

Hasil penelitian menjelaskan bahwa: Repositioning L-Men merupakan strategi komunikasi yang dilakukan oleh manajemen L-Men sebagai komunikator yang terdiri dari brand marketing, digital, public relations, customer relations, promotions (SPG), serta melibatkan pihak eksternal seperti Perbasi dan atlet-atlet non-gym, dengan pesan yang ingin disampaikan adalah L-Men merupakan produk untuk membentuk tubuh yang ideal dan atletis, melalui media serta berhadapan langsung dengan audiens melalui event dan program, dengan target sasaran pria berusia 17 sampai 35 tahun yang menyukai gaya hidup sehat dan membutuhkan nutrisi untuk pembentukan massa otot dan meningkatkan performa olahraga, dengan efek yang diharapkan adalah meningkatkan awareness produk dan meningkatkan jumlah penjualan. Atribut-atribut yang dimiliki L-Men dalam repositioning adalah desain packaging, konsep iklan, konten marketing, dan event. Repositioning ini dinyatakan dalam positioning statement, yaitu "Nutrisi Efektif untuk Pria Membentuk Tubuh Ideal dan Atletis".

\section{Kata kunci: implementasi, repositioning, atribut}

\section{PENDAHULUAN}

Pada dasarnya, sebuah produk memiliki tahap siklus produk atau yang dikenal sebagai product life cycle, yaitu mulai dari tahap introducing, growth, lalu tahap puncaknya yaitu maturity, dan secara alamiah akan menurun hingga tahap decline. Sebuah produk yang baru mulai memasuki tahap introducing, tentu akan mudah untuk naik ke tahap growth, apabila memiliki diferensiasi yang kuat dengan segmentasi pasar yang potensial juga. Begitu juga dengan pada tahap growth, akan mudah untuk mencapai tahap maturity apabila berhasil bersaing dengan para kompetitornya, serta telah berhasil memperkuat positioningnya di benak konsumen sehingga menjadi produk yang top of mind. Namun, sebuah produk akan lebih kesulitan mempertahankan posisinya di tahap maturity, karena apabila produk tersebut tidak dikembangkan lebih lanjut tentu secara alamiah akan menuju tahap selanjutnya yaitu decline. 
Di dalam dunia bisnis, tentu sebagai seorang pebisnis harus bisa memprediksi bagaimana kelanjutan tahap siklus produknya. Upaya membangun produk hingga masuk ke tahap maturity tentu bukan usaha yang mudah, apalagi dalam mempertahankannya. Tentu perlu analisis yang tepat dalam menentukan langkah selanjutnya agar tidak menghancurkan hasil yang telah dibangun sejak awal. Akan tetapi, terlalu ketatnya persaingan dalam dunia bisnis juga membuat para pelaku bisnis tidak bisa berdiam diri karena banyak para kompetitor yang siap untuk menggeser posisinya. Jadi seorang pebisnis harus bisa menentukan langkah yang akan diambil agar posisi produknya yang sudah di tahap maturity, tidak menurun ke tahap decline tapi justru semakin berkembang dan kian menaik, tanpa harus menghancurkan hasil yang sudah dicapai.

Hal ini disadari oleh manajemen L-Men terhadap produknya. Produk LMen yang sudah ada sejak tahun 2001 sudah berkembang menjadi produk yang sudah berada di tahap maturity dan memiliki positioning yang kuat. Sebagai produk yang sudah di tahap maturity dan memiliki positioning yang kuat membuat produk L-Men rentan mengalami stagnansi dalam penjualan. Hal yang dilakukan oleh manajemen untuk mengatasi permasalahan tersebut yaitu dengan melakukan strategi repositioning terhadap produknya, karena stagnansi penjualan merupakan suatu tanda dimana produk harus melakukan strategi repositioning. Seperti yang dijelaskan oleh Belch dan Belch bahwa strategi yang dilakukan kala terjadi suatu kondisi dimana sebuah produk mengalami sebuah kevakuman oleh stagnansi penjualan, atau oleh karena kesulitan untuk menyempurnakan dan menerapkan strategi, dimana hal tersebut terjadi karena terhalang oleh persepsi atas sikap konsumen terhadap produk atau merek yang ditawarkan. (Soemanagara, 2012:18)

L-Men melakukan repositioning terhadap produknya karena manajemen menyadari bahwa positioning lamanya yang hanya berfokus kepada satu segmen pasar membuat pasar dari produk L-Men menjadi terlalu sempit, serta adanya pasar yang potensial bagi L-Men untuk berpeluang dalam memperluas pasarnya. Akan tetapi, fokusnya L-Men selama ini kepada satu segmen pasar saja membuat produknya sulit diterima oleh target pasar yang baru. Maka dari itu, L-Men ingin melebarkan fokusnya dan menanamkan image baru (repositioning) produknya agar bisa diterima oleh target pasar yang baru.

Untuk mengubah positioning yang lama di benak konsumen dan mendukung positioning yang baru, L-Men melakukan beberapa implementasi untuk menyampaikan pesan repositioning barunya. Mulai dari melalui strategi komunikasi yang dilakukan, lalu mengubah atribut-atribut produknya, serta mengubah positioning statementnya. 
Perubahan-perubahan yang dilakukan oleh L-Men merupakan wujud usaha L-Men untuk meninggalkan image lamanya dan membentuk image yang baru. Konsep yang diterapkan lebih menekankan pada olahraga dan anak muda agar sesuai dengan preferensi target pasar barunya, yaitu dunia olahraga untuk 16 tahun ke atas.

Akan tetapi, implementasi yang dilakukan oleh L-Men tidak juga dapat mencapai tujuan repositioning L-Men, yaitu mengubah persepsi calon konsumennya. Dalam implementasi repositioning L-Men ditemukan adanya unsur-unsur atribut L-Men yang tidak diubah. L-Men hanya melakukan perubahan pada unsur kemasan, sedangkan unsur lainnya seperti merek, pemberian label, layanan pelengkap, dan garansi tidak dilakukan perubahan. Hal ini yang kurang mendukung dalam mencapai tujuan repositioning.

Dari fenomena-fenomena tersebut, fokus yang peneliti coba untuk dirumuskan pada penelitian ini adalah: "Bagaimana implementasi repositioning LMen dari nutrisi efektif untuk membentuk tubuh atletis dan performa pria aktif menjadi nutrisi efektif untuk pria membentuk tubuh ideal dan atletis."

Identifikasi masalah dalam penelitian ini antara lain: (1) Bagaimana strategi komunikasi yang dilakukan L-Men dalam menerapkan repositioning (2) Bagaimana atribut-atribut produk yang disampaikan L-Men dalam menerapkan repositioning (3) Bagaimana positioning statement baru yang dimiliki L-Men dalam menerapkan repositioning.

\section{KERANGKA PEMIKIRAN}

Menurut Soemanagara (2012:48), unsur dari komunikasi pemasaran atau komunikasi pemasaran mix terdiri dari advertising, sales promotion, publicity, personal selling, dan direct selling. Bentuk komunikasi yang digunakan advertising atau periklanan merupakan komunikasi massa melalui media. Seperti yang dijelasakan oleh Soemanagara (2012:49) bahwa periklanan merupakan kegiatan komunikasi pemasaran yang menggunakan media massa dalam proses penyampaiannya. Griffin dan Ebert (dalam Soemanagara, 2012:49) juga menyebutkan bahwa "Advertising is paid, non personal communication used by an identified sponsor to inform an audience about product". Tujuan dari iklan adalah untuk meningkatkan terjadinya perubahan sikap dan perilaku konsumen. Periklanan memiliki karakteristik dapat mencapai konsumen yang terpencar secara geografis, dapat mengulang pesan berkali-kali, bersifat impersonal dan komunikasi satu arah, dan dapat sangat mahal untuk beberapa jenis media (Hermawan, 2012:54). 
Selanjutnya repositioning. Repositioning memiliki arti sebagai menetapkan positioning kembali, yang mana positioning sendiri didefinisikan oleh Philip Kotler (dalam Kasali, 1998:526) sebagai,

"the act of designing the company's offering and image so that they occupy a meaningful and distinct competitive position the target customers mind". (Positioning adalah tindakan yang dilakukan marketer untuk membuat citra produk dan hal-hal yang ingin ditawarkan kepada pasarnya berhasil memperoleh posisi yang jelas dan mengandung arti dalam benak sasaran konsumennya).

Definisi di atas dapat menjelaskan bahwa tujuan dari strategi positioning adalah memperoleh posisi yang jelas dan mengandung arti dalam benak sasaran konsumennya. Hal tersebut menjadi sangat penting karena begitu ketatnya persaingan dalam pasar membuat sebuah produk rentan untuk dilupakan oleh para konsumennya. Maka dari itu, sebuah produk memerlukan positioning yang kuat untuk dapat bertahan dalam ketatnya persaingan pasar.

\section{METODE PENELITIAN}

Penelitian ini menggunakan metode penelitian deskriptif. Penelitian deskriptif (Faisal (2007:20) dimaksudkan untuk eksplorasi dan klarifikasi mengenai sesuatu fenomena atau kenyataan sosial, dengan jalan mendeskripsikan sejumlah variabel yang berkenaan denan masalah dan unit yang diteliti. Rakhmat (2009:24) menjelaskan bahwa penelitian deskriptif hanyalah memaparkan situasi atau peristiwa. Penelitian ini tidak mencari atau menjelaskan hubungan, tidak menguji hipotesis atau membuat prediksi

Penelitian deskriptif menurut Rakhmat (2009:25). ditujukan untuk: (1) mengumpulkan informasi aktual secara rinci yang melukiskan gejala yang ada Dalam penelitian ini, peneliti mengumpulkan informasi dari berbagai narasumber yang merupakan key informant secara dengan menggunakan pedoman wawancara yang sudah dipersiapkan secara rinci untuk mendapatkan informasi yang aktual dan rinci. (2) Mengidentifikasi masalah atau memeriksa kondisi dan praktekpraktek yang berlaku. Peneliti akan memeriksa data yang diperoleh dari wawancara dan observasi dan mengidentifikasi permasalahan apa yang terjadi, memeriksa kondisi, serta mengetahui bagaimana implementasi repositioning LMen dilakukan. (3) Membuat perbandingan atau evaluasi. Peneliti akan membuat perbandingan dan menganalisis data yang diperoleh berdasarkan tinjauan pustaka yang ada. (4) Menentukan apa yang dilakukan orang lain dalam menghadapi masalah yang sama dan belajar dari pengalaman mereka untuk menetapkan 
rencana dan keputusan pada waktu yang akan datang. Proses pengumpulan data menggunakan teknik-teknik observasi, wawancara, dan studi pustaka.

Subjek dari penelitian ini merupakan individu-individu yang memang terlibat dalam pelaksanaan repositioning, dari masa perencanaan hingga pelaksanaan. Teknik analisis data yang digunakan adalah teknik analisis data model Miles dan Huberman, yang mana aktivitas dalam analisis data model Miles dan Huberman, yaitu data reduction, data display, dan conclusion drawing/verification. Untuk mengecek keabsahan data, peneliti menggunakan triangulasi sumber.

\section{HASIL PENELITIAN DAN PEMBAHASAN}

Pada dasarnya sebuah strategi dibuat atau dilakukan berdasarkan sebuah alasan dan tujuan. Strategi Repositioning menurut penjelasan dari Belch dan Belch adalah:

"Strategi yang dilakukan kala terjadi suatu kondisi dimana sebuah produk mengalami sebuah kevakuman oleh stagnansi penjualan, atau oleh karena kesulitan untuk menyempurnakan dan menerapkan strategi, dimana hal tersebut terjadi karena terhalang oleh persepsi atas sikap konsumen terhadap produk atau merek yang ditawarkan.” (Soemanagara, 2012:18)

L-Men sebagai produk niche market memiliki segmentasi pasar yang berfokus pada pria yang melakukan aktivitas gym, sehingga membuat L-Men rentan dengan jumlah penjualan yang stagnan atau tidak adanya perkembangan pasar. Oleh karena itu, strategi repositioning merupakan langkah yang tepat untuk dilakukan oleh manajemen L-Men.

Tidak hanya itu, ada beberapa hal yang menjadi alasan mengapa stategi repositioning harus dilakukan seperti yang dijelaskan oleh Hermawan Kartajaya:

Ada empat kemungkinan alasan bagi perusahaan atau produk untuk melakukan strategi repositioning yaitu, (1) reaksi atas posisi baru pesaing, (2) menggapai pasar baru, (3) menangkap trend baru, dan (4) mengubah value offering.(Kartajaya, 2005:96-104)

Sesuai dengan penjelasan dari Hermawan Kartjaya, alasan L-Men melakukan repositioning adalah untuk memperluas segmentasi pasar dan adanya target segmentasi pasar baru yang potensial.

Pada dasarnya, repositioning adalah melakukan positioning ulang. Dilihat dari berbagai definisi yang telah dijelaskan sebelumnya, terdapat hal-hal yang perlu diperhatikan dalam melakukan implementasi positioning/ repositioning. Kasali (1998:527-533) menjelaskan bahwa positioning/ repositioning merupakan 
strategi komunikasi, berhubungan dengan atribut-atribut produk, serta positioning/ repositioning harus diungkapkan dalam positioning statement.

Pertama, positioning/ repositioning merupakan strategi komunikasi (Kasali, 1998:527). Adapun pesan baru terkait positioning baru L-Men yang disampaikan melalui strategi komunikasi. Komunikator pada strategi komunikasi dalam repositioning L-Men adalah tim manajemen L-Men yang terdiri dari brand marketing, digital, public relations, customer relations, promotions, serta pihak eksternal yang terlibat adalah Perbasi dan atlet-atlet non-gym. Pesan yang disampaikan adalah L-Men adalah produk untuk membentuk tubuh yang ideal dan atletis. Media yang digunakan adalah media digital seperti website dan social media, media massa seperti televisi, serta melalui event dan program. Komunikan dari strategi komunikasi yang dijalankan adalah pria dengan usia aktif 17 tahun sampai 35 tahun, yang menyukai gaya hidup sehat, dan membutuhkan nutrisi untuk pembentukan massa otot dan meningkatkan performa olahraga.

Untuk menjawab efek seperti apa yang sebenarnya ingin didapatkan dalam strategi repositioning, bisa kita lihat penjelasan dari Hiebing \& Cooper berikut ini,

"Positioning establishes the desired perception of your product within the target market relative to the competition. (Positioning membangun persepsi yang diinginkan dari sebuah produk di dalam target pasar relatif terhadap persaingan)." (Kasali, 1998:526)

Hasil dari dilakukannya strategi repositioning yaitu terbentuknya persepsi yang diinginkan dari sebuah produk di dalam benak target pasar. Ketika target pasar memiliki persepsi yang baik dan sesuai dengan keinginan marketer, maka selanjutnya diharapkan dapat mendorong adanya peningkatan penjualan. Begitu juga dengan yang Tjiptono (2008:111) jelaskan bahwa "kunci utama keberhasilan positioning terletak pada persepsi yang diciptakan".

Efek yang diharapkan dalam menjalankan strategi komunikasi L-Men dalam repositioning, pertama, meningkatkan awareness tentang produk L-Men kepada target konsumen yang baru bahwa L-Men cocok dikonsumsi bagi anak muda yang melakukan aktivitas olahraga apapun. Kedua, diharapkan dengan adanya target pasar yang lebih luas mendorong kenaikan penjualan.

Kedua, positioning/ repositioning berhubungan dengan atribut-atribut produk (Kasali, 1998:532). Kasali menjelaskan bahwa konsumen pada dasarnya tidak membeli produk, tetapi mengkombinasikan atribut. Atribut produk meliputi merek, kemasan, pemberian label (labeling), layanan pelengkap (supplementary services), dan jaminan (garansi) (Tjiptono, 2008:104-108).

Untuk mendukung keberhasilan repositioning L-Men, manajemen melakukan beberapa perubahan pada atribut agar dapat masuk ke dalam preferensi 
pasar yang baru. Perubahan yang pertama terletak pada desain packaging produk L-Men. Sebelumnya di setiap packaging L-Men selalu terdapat gambar model laki-laki dengan tubuh atletis, tetapi sekarang dihilangkan. Hanya ada dua varian produk yang menggunakan gambar model laki-laki pada packaging, yaitu varian untuk menurunkan berat badan dan meningkatkan berat badan. Hal tersebut untuk menjelaskan manfaat produk lebih mudah, yaitu dengan adanya transformasi. Desain packaging yang sekarang juga lebih clean dan bermain blocking warna, agar kemasan produk terlihat lebih premium.

Perubahan yang kedua terletak pada konsep iklan, mulai dari iklan televisi maupun iklan di social media atau digital. Konsep iklan yang sebelumnya, L-Men selalu menampilkan pria dewasa dengan tubuh atletis yang menggoda para wanita. Tetapi sekarang diubah menjadi anak muda dan aktivitas olahraga. Penggunaan kata-katanya juga disesuaikan dengan gaya bahasa anak muda dan talent nya juga diganti menjadi anak muda, bukan pria dewasa. Jadi, konsep iklan yang baru lebih down-to-earth dan mengacu kepada aktivitas keseharian anak muda, seperti olahraga.

Perubahan yang ketiga terletak pada konten marketing dan artikel. Gaya bahasa pada konten disesuaikan dengan gaya bahasa anak muda, agar lebih dekat dengan target konsumen. Selain itu, konten artikel juga diubah, yang sebelumnya terlalu fokus dengan topik gym, sekarang lebih membahas olahraga secara umum.

Perubahan yang keempat adalah aktivitas below the line yaitu event. Sebelumnya L-Men dikenal melalui acara besar tahunannya, yaitu L-Men of The Year. Event yang menggantikan L-Men of The Year adalah L-Men 3X3. L-Men 3X3 merupakan acara turnamen basket 3X3 yang diselenggarakan bersama Persatuan Basket Indonesia (Perbasi). Peran acara ini cukup besar untuk mengubah persepsi calon konsumen terhadap produk L-Men, karena di dalam acara ini terdapat komunikasi langsung atau berhadapan langsung dengan target audiens, bahwa L-Men cocok untuk dikonsumsi bagi anak muda yang menyukai olahraga, apapun olahraganya.

Atribut-atribut yang dimiliki L-Men dapat menjadi lebih unggul karena konten yang dibuat berdasarkan riset dan jurnal agar terjaga kredibilitasnya; label produk menjelaskan kelebihan-kelebihan produk L-Men dari segi kandungan, dan adanya sertifikasi halal dan BPOM; serta belum adanya brand yang menggarap olahraga basket 3X3 sebelumnya dan skala acara yang besar hingga internasional. Alasan menciptakan atribut produk tersebut adalah agar dapat menjangkau target audiens yang baru. Atribut-atribut L-Men dapat membangun utility dengan membentuk brand L-Men sebagai brand yang tidak hanya menjual produk, melainkan juga edukasi agar konsumen paham mengenai produk L-Men. 
Ketiga, positioning harus diungkapkan dalam bentuk suatu pernyataan (positioning statement) (Kasali, 1998:533). Positioning statement L-Men dalam repositioning adalah "Nutrisi efektif untuk pria mendapatkan tubuh ideal dan atletis." Makna dari positioning statement tersebut adalah L-Men merupakan asupan nutrisi yang efektif dari dalam untuk pria mendapatkan hasil tubuh yang atletis dan ideal dengan diimbangi aktivitas olahraga apapun. Alasan memilih positioning statement tersebut adalah untuk memenuhi keinginan konsumen LMen yang menginginkan hasil dari mengonsumsi produk L-Men, yaitu bentuk tubuh ideal dan atletis.

Kotler (2005:345) juga menjelaskan bahwa pernyataan itu harus berbentuk: Bagi (kelompok dan kebutuhan sasaran) (Merek) kami merupakan (konsep) yang (kekhasan). Artinya sebuah pernyataan positioning harus menjelaskan siapa target sasarannya, merek yang dijual, konsep dari produk tersebut yang memiliki kekhasan sehingga menjadi nilai jual dari produk tersebut. Positioning statement L-Men menggambarkan tiga hal, yaitu: konsep produk L-Men, siapa target audiens L-Men, dan manfaat produk L-Men.

Agar positioning statement L-Men dapat dipercaya dilakukan upaya seperti mengedukasi target audiens dengan materi yang berasal dari riset dan jurnal agar terjaga kredibilitasnya, dan semua pesan repositioning dikomunikasikan secara konsisten dan sejalan.Cara positioning statement L-Men agar mudah diucapkan, enak didengar, dan dianggap unik dilakukan adalah dengan menyesuaikan dari insight konsumen, serta membuat konsep digital marketing dan acara yang unik.

\section{KESIMPULAN}

Berdasarkan hasil dan pembahasan dalam penelitian ini, peneliti dapat menyimpulkan bagaimana strategi komunikasi L-Men dalan repositioning, atribut-atribut L-Men dalam repositioning, serta positioning statement L-Men dalam repositioning, sebagai berikut:

1. Strategi repositioning yang dilakukan L-Men merupakan strategi komunikasi dengan tujuan untuk memperluas segmentasi pasar dari produk L-Men. Perluasan segmentasi pasar ini juga berdasarkan adanya target segementasi pasar baru yang potensial bagi L-Men, yaitu anak muda yang gemar berolahraga dan mulai peduli dengan penampilan.

2. Atribut-atribut yang dimiliki L-Men dalam repositioning adalah desain packaging yang lebih clean dan kelihatan premium, konsep iklan yang berfokus pada olahraga untuk segmentasi anak muda, konten marketing yang diperluas dengan membahas olahraga secara umum, serta event 
olahraga seperti L-Men 3X3 dan acara yang mensponsori olahraga lainnya. Atribut-atribut L-Men menjadi lebih unggul karena adanya diferensiasi dengan kompetitornya.

3. Positioning statement L-Men dalam repositioning adalah "Nutrisi efektif untuk pria mendapatkan tubuh ideal dan atletis". Positioning statement LMen yang baru memiliki arti bahwa L-Men merupakan asupan nutrisi yang efektif dari dalam untuk pria mendapatkan hasil tubuh yang atletis dan ideal dengan diimbangi aktivitas olahraga apapun. Sebab dipilihnya positioning statement tersebut adalah untuk memenuhi keinginan konsumen L-Men yang menginginkan hasil dari produk L-Men yaitu bentuk tubuh ideal dan atletis.

Berdasarkan hasil penelitian ini, ada beberapa saran yang diberikan, diantaranya: Riset yang dilakukan oleh manajemen terhadap target pasar dan atribut yang dipilih harus lebih dalam lagi. Selain itu, sebaiknya L-Men juga melakukan riset kepada target yang lama berkaitan dengan adanya repositioning ini. Dengan adanya perubahan segmentasi menjadi lebih umum dari yang awalnya merupakan produk niche bisa membuat sebuah produk downgrade atau turun menjadi produk yang biasa saja di mata konsumen sebelumnya. Mengenai atribut, L-Men dirasa perlu membuat acara lain untuk target pasar yang lama setelah meniadakan acara tahunannya L-Men of The Year. Hal ini bertujuan untuk mempertahankan loyalitas dan komunikasi dengan konsumen lama. Tidak samanya positioning statement dengan slogan produk yang dimiliki L-Men tentu akan membuat positioning statement diucapkan tersirat sehingga kurang didengar oleh publik dibanding slogannya. Perlu adanya pengulangan secara intens di setiap media untuk membantu agar positioning statement yang baru dapat menjadi top of mind di benak publik.

\section{UCAPAN TERIMA KASIH}

Penyelesaian artikel ini tidak lepas dari bantuan serta dukungan banyak pihak, untuk itulah dalam kesempatan ini penulis ingin mengucapkan terima kasih kepada :

Seluruh narasumber dan triangulator: Bapak Meirza, Ibu Arninta, Bapak Ganda, Bapak Iwang, Bapak Nova, Bapak Deru, Mas Kenny, dan Mas Ario, yang dengan baik hatinya dapat meluangkan waktu untuk berbagi informasi sehingga artikel ini dapat diselesaikan.

\section{DAFTAR PUSTAKA}


Faisal, Sanapiah. 2007. Format-Format Penelitian Sosial. Jakarta: RajaGrafindo Persada

Hermawan, Agus. 2012. Komunikasi Pemasaran. Jakarta: Erlangga

Kartajaya, Hermawan. 2005. Positioning, Diferensiasi, dan Brand.Jakarta: PT Gramedia Pustaka Utama

Kasali, Rhenald. 1998. Membidik Pasar Indonesia. Jakarta: Gramedia Pustaka Utama

Kotler, Philip. 2005. Manajemen Pemasaran Edisi Kesebelas. Jakarta: PT INDEKS Kelompok Gramedia

Rakhmat, Jalaluddin. 2009. Metode Penelitian Komunikasi. Bandung: Remaja Rosdakarya

Soemanagara, Rd. 2012. Strategic Marketing Communication. Bandung: Alfabeta

Tjiptono, Fandy. 2008. Strategi Pemasaran. Yogyakarta: Penerbit ANDI 